\title{
BRUJOS Y BRUJAS EN EL ANTIGUO PERU: APARIENCIA Y REALIDAD EN LAS FUENTES HISTORICAS
}

\author{
POR \\ IRIS GAREIS \\ Institut für Volkerkunde \\ Munich
}

\author{
"Bruja joven; \\ Los polvos, como las sayas, \\ están bien para las viejas \\ por eso yo monto en cueros \\ en mi cabrón, y así exhibo \\ orgulloso, el bello cuerpo" (1)
}

El término "brujo" y especialmente el de "bruja» evocará en muchos lectores la imagen de una mujer joven y bonita o vieja y fea, desplazándose por el aire montada en una escoba, para acudir al sabbat, con el fin de adorar al diablo y de practicar la magia negra. Este es el retrato de la "bruja» que pintaron sus jueces, los "cazadores de brujas", particularmente en los siglos XV al XVII. En una multitud de tratados teóricos y en la práctica procesal establecieron una noción especifica, un estereotipo de la "bruja" que - aunque con modificaciones- se perpetuó en la tradición popular hasta el presente (2). Más adelante nos ocupa-

SIGI.AS UTII.IZADAS:

AGI: Archivo General de Indias, Sevilla

CLDHP: Colección de Libros y Documentos referentes a la Historia del Perú. Lima 1919

RAH: Real Academia de la Historia, Madrid

El presente artículo se basa en una conferencia dictada en diciembre de 1987

en el Instituto Ibero-Americano (Ibero-Amerikanisches Institut PK) de Berlín. Agradecemos a María Susana Cipolletti la lectura crítica del manuscrito. Nuestros estudios archivísticos fueron posibles gracias a una beca de la Fundación Alemana de Investigación Científica (DFG-Deutsch Forschungsgemeinschaft).

(1) Johann Wolfgang von Gorthe, "Fausto", en Obras Completas. Madrid, Aguilar 1973, tomo III, Primera Parte, Escena XXII, pág. 1.365.

(2) Acerca de este concepto y de su evolución véanse: Hanns BächtoldStäuBi.ı, Handwörterbuch des deutschen Aberglaubens. Walter de Gruyter (Berlin y Leipzig, 1927-1942). 10 tomos. Citas en t. III (1930/31), pags. 1.827-1.830, 1.8421.852. Wolfgang Bithringier, "'Vom Unhraut unter dem Weizen'. Die Stellung der 
remos detenidamente de este estereotipo de la "bruja». En el marco del presente artículo hemos optado por una definición más amplia del término: aquí entendemos por "brujos" y "brujas» a todos los individuos que dañan o intentan dañar a otras personas por medio de artes mágicas (3).

Los propósitos de nuestro estudio consisten en averiguar si tales brujos existieron en el antiguo Perú, y si esto se comprobara, en determinar cómo estaban organizados, cuáles fueron sus funciones y qué papel desempeñaron en las sociedades prehispánicas de los Andes Centrales.

El marco geográfico de nuestro trabajo está dado por el núcleo del imperio incaico, es decir la región andina y la costa del Perú actual. El periodo temporal abarca los últimos decenios que precedieron a la conquista española.

\section{PROBLEMAS DE LA RECONSTRUCCIÓN HISTÓRICA}

Al intentar formarse una idea clara sobre los brujos del antiguo Perú se presentan múltiples dificultades: Un primer obstáculo surge del hecho que todos los testimonios escritos que proporcionan informaciones sobre los brujos en las sociedades andinas prehispánicas fueron redactados varias décadas después de la conquista española. Desde la caída del imperio incaico hasta entonces ya habian transcurrido muchos años y al igual que otras instituciones andinas, podemos suponer que el oficio del brujo - si realmente existió antes de la llegada de los españoleshabía sufrido cambios profundos, causados por el impacto de la Conquista.

A este problema de la reconstrucción histórica se une otro, no menos intrincado: La mayoría de los autores de los textos

Kirchen zum Hexenproblem", en Richard van Dülmen (ed.), Hexenwelten. Magie und Imagination vom 16. - 20. Jahrhundert. Fischer Taschenbuch Verlag (Frankfurt/M., 1987), págs. 15-47. Citas en págs. 23-27, passim. Julio CARO BAROJA, Las brujas y su mundo. Alianza Editorial (Madrid, 1988). Citas en págs. 109-110, 114 120, 124-132, 149-161. Emmanuel Le Roy LadURIE, La Sorcière de Jasmin. Con el Tacsimil del original bilingüe de la Françouneto de Jasmin (1842) Ed. du Seuil (Paris, 1983). Citas en págs. 67-69, 273-274 nota 97. La imagen europea de la bruja fue compuesta de elementos procedentes de las tradiciones tanto popular como también erudita: veáse Richard van DülLMEN, "Imaginationen des Teuflischen. Nächtliche Zusammenkünfte, Hexentänze Teufelssabbatte", en Düı.mFN, págs. 94130. Citas en págs. 97-98, 107-112, 129-130.

(3) Véase por ejemplo Inge Sснӧск, "Hexen heute. Traditioneller Hexenglaube und aktuelle Hexenwelle", en Dülmen [2], págs. 282-305. Citas en págs. 286, 301. 
sobre la brujería prehispánica eran españoles. No solamente tenían escasos conocimientos de la religión andina de los primeros decenios posteriores a la Conquista - como sugiere gran parte de las obras redactadas por entonces-, sino que también solían distorsionar los datos históricos (4), interpretándolos a base de sus propios conceptos europeos (5). En consecuencia, las informaciones proporcionadas por los autores españoles de la época colonial temprana, además de ser incompletas, presentan frecuentemente considerables alteraciones. Es de suponer que las lagunas en las fuentes y las distorsiones de los datos fueron mayores, cuanto menos sabían los escritores españoles del fenómeno que describían, y que esto aconteció particularmente con materias tan delicadas como la brujería, que ya de por si se presta a falsificaciones. Puede suponerse que muchas informaciones sobre los brujos del antiguo Perú escaparon a la atención de los observadores contemporáneos porque éstos no percibieron su importancia, y otras fueron alteradas, cuando los autores trataron de llenar los vacíos en sus textos, completándolos con datos de sus propios conocimientos. De ahí que sea necesario ocuparse también del estereotipo de la «bruja», que mencionamos en la introducción. Aunque éste fue aparentemente más bien un modelo teórico, elaborado por demonólogos y jueces de la Inquisición antes que una representación real, no debemos descartarlo de nuestras consideraciones, porque ésta era precisamente la visión más divulgada entre los autores españoles de la época colonial temprana (6).

Finalmente no podemos dejar de mencionar otro problema importante, intrínseco a las fuentes históricas: El de la terminología usada en los textos respectivos. Con frecuencia los autores contemporáneos -españoles e incluso indígenas- aplicaban los términos brujos o hechiceros indistintamente a los especialistas religiosos andinos, aunque éstos eran en realidad sacerdotes o curanderos, y sólo pocas veces se trataba de «brujos» que em-

(4) Compárese Thomas Hauschild, "Hexerei", en Bernhard STReck (ed.), Wörterbuch der Ethnologie. Du Mont Colonia (1987), págs. 82-85. Citas en págs. 82-83.

(5) Esta conducta de los escritores europeos contemporáneos fue caracterizada muy bien por Silverblatt, advirtiendo que aquéllos autores percibían la realidad andina sólo a través de su "lente cultural" (Irene SilverblatT, "The Evolution of Witchcraft and the Meaning of Healing in Colonial Andean Society", en Culture, Medicine, and Psychiatry n 7, Dordrecht, 1983, págs. 413-427. Citas en págs. 413-414., o sea un "lénte distorsionado" (I. Sil.verbi.ATT, "Dioses y diablos: Idolatrias y Evangelizacion", en Allpanchis Phuturinga XVI, no 19 Cuzco, 1982, págs. 31-47. Cita en pág. 38).

(6) Véase Pierre Duviols, Cultura andina y represión. Procesos y visitas de idolatrias y hechicerias, Cajatambo, siglo XVII. Centro de estudios rurales andinos "Bartolomé de las Casas", Cuzco, 1986. Citas en págs. LXVIII-LXXII. 
pleaban maleficios. Por eso nuestra primera tarea consiste en averiguar cuáles de las múltiples citas sobre hechiceros se refieren realmente a brujos, según nuestra definición (7).

\section{BRujos en el antiguo Perú}

Comencemos por revisar los datos sobre ciertos adivinos, mencionados por varios autores de los siglos XVI y XVII (8). Sometiendo estos escritos a una rigurosa crítica de fuentes, descubrimos que todos los testimonios se remontan a un sólo texto (9): El tratado de Polo de Ondegardo sobre la religión de los indígenas del Perú. El original se ha perdido, pero un compendio de esta obra se publicó en 1585 en el Confessionario para curas de indios (10).

(7) La distinción hecha aquí entre "brujos" y "hechiceros" corresponde al modo cómo estos términos son empleados en las fuentes históricas utilizadas en el presente trabajo y es válida sólo dentro del margen de éste. No aspiramos a sugerir una definición general, ya que ésta depende en gran parte de la problemática que se pretende estudiar. Así por ejemplo, CARO BAROJA [2] cita en pág. 112, ha optado por distinguir estos términos de otra manera. Acerca de la diferencia entre los conceptos de "brujeria" y de "hechicería", véase también DülmEN [2] citas en págs. 98-99), quien hace referencia a informaciones de regiones de habla alemana.

(8) José de AcosTa, Historia/ natvral/ y/ moral de las/ Indias, en que se tratan las cosas / notables del cielo, y elementos, metales, plantas, $v$ anima-/les dellas: y los ritos, y ceremonias, leyes, y/ gouierno, y guerras de los Indios. / Juan de León, Sevilla, 1590. Cita en Lib. V cap. XXVI, pag. 372; Bernabé CoBo, Historia del Nuevo Mundo. Madrid, 1956, Biblioteca de autores españoles págs. 91-92. Citas en Lib. XIII cap. XXXVI, págs. 230-231; Martín de MurUA, Historia general del Perú. Madrid, 1962-1964. Instituto Gonzalo Fernández de Oviedo, Citas en t. 2, Lib. II cap. 32, págs. $117-118$ fs. 264-265.

(9) Hecho que en los estudios modernos frecuentemente ha pasado inadvertido. SilverblatT [5], pág. 37 cita, por ejemplo, el texto respectivo de la obra de Acosta sin hacer referencia al auténtico autor de esta afirmación ni señalar las relaciones de dependencia entre estas fuentes históricas.

(10) Acerca de la historia del texto de Ondegardo véase Pierre Duviols, La lutte contre les religions autochthones dans le Pérou colonial. L'extirpation de l'idotatrie entre 1532 et 1660. Linea Travaux de l'Institut Français d'Études Andines 13. Institut Français d'Etudes Andines 1971; cita en pág. 100. Es de destacar que Acosta fue uno de los personajes encargados de la redacción del "Confessionario" y por lo tanto conocio probablemente incluso el original de la relación de Polo (vease la "Provisión Real", en Confessionario/ para los cvras/ de indios/ con la instrvcion contra svs/ ritos y exhorlacion para ayudar a bien morir y sum-/ma de sus privilegios y forma de Impedi-/mentos del Matrimonios. / Compvesto y tradvcido en las Lenguas Quichua y Aymara. Por autoridad del Concilio/ Prouincial de Lima, del año de 1583. Antonio Ricardo (Los Reyes 1585). Existe edición facsímil, Madrid, CSIC, 1985. Las analogías sorprendentes entre el libro de Murúa $y$ los textos insertos en el Confessionario fueron destacadas extensamente por Pierre Düviol,s, "Les sources religieuses du chroniqueur péruvien Fray Martín de Morua", en Études Latino-Américaines I, Aix-en-Provence, 1962, págs. 33-43. Citas en págs. 34-36, passim. 
Polo caracterizó estos adivinos en la siguiente forma:

Otro género de hechizeros auía..., permitidos por los Yngas en cierta manera, que son como brujos. Que toman la figura que quieren y van por el ayre en breue tiempo, mucho camino; y ven lo que passa, hablan con el demonio, el cual les responde en ciertas piedras, ó en otras cosas... Estos siruen de adiuinos, y de dezir lo que passa en lugares muy remotos, antes que venga ó pueda venir la nueua... el mesmo día y el tiempo que las tales cosas sucedieron, ó el día siguiente, que por curso natural era impossible saberlas tan presto (11).

En la descripción de Polo los rasgos más predominantes de estos especialistas religiosos son su capacidad de transformación, adopción de otra figura y su desplazamiento por el aire. Según Polo ni lo uno ni lo otro podía efectuarse de manera natural, pero en el curso de su texto halla una posible explicación para eso,

pues "algunos dizen y afirman que éstos vsan de ciertas vnturas (12)

Nuestro autor afirma además, que en el tiempo prehispánico solían ser mujeres viejas quienes ejercían este oficio (13). Es fácil reconocer aquí varios elementos constitutivos del estereotipo europeo de la bruja, establecido desde la publicación del Malleus maleficarum, o sea el "Martillo de las brujas", en el año 1487, que es considerado como uno de los manuales más importantes de las grandes campañas de persecución de las brujas en Europa (14)

Algunas de las afirmaciones de Polo, como su insistencia en que la brujeria era ejercida sobre todo por mujeres viejas, o que los brujos tenían la capacidad de volar y de transformarse, como también el pretender que usaban para ello un ungüento, indican

(11) Juan Polo de Ondegardo, "Los errores y supersticiones de los indios, sacadas del tratado y averiguación que hizo el Licenciado Polo", en Horacio URTEAGa y Carlos Romero eds., Informaciones acerca de la Religión y Gobierno de los Incas. Colección de libros y documentos referentes a la Historia del Perú (Serie I, tomo 3, Lima, 1916, págs. 3-43. Cita en cap. X, pág. 29.

(12) Idem cap. X, pág. 29.

(13) Idem, ibidem

(14) Veánse Bächtold-STÄubli [2], pág. 1.828, 1.838-1.842; BEhringer [2], págs . 26-30; Caro Baroja [2], págs. 125, [27-132, 309-310, passim y Le Roy LaduRie [2], pág. 15 . 
claramente que su descripción de los brujos andinos se hallaba fuertemente influida por la imagen europea de la bruja. Por cierto esta influencia nunca fue negada por el autor español, más bien la hizo resaltar, escribiendo que estos adivinos eran "como brujos". Es decir que aludió explícitamente a un concepto preciso de brujos, bien conocido por sus lectores.

Polo de Ondegardo había 'adquirido el título de licenciado, probablemente en la Universidad de Salamanca (15), y era considerado un hombre erudito (16) Es de suponer que sus conocimientos sobre la brujería europea no se fundaban en rumores, sino que más bien eran fruto de la lectura detenida de las obras contemporáneas sobre esta problematica. En aquélla época gozaba de gran popularidad en España un manual sobre este tema del famoso matemático y teólogo Pedro Ciruelo, que fue editado varias veces durante el siglo XVI y obtuvo una gran divulgación (17). Quien atribuía, por 1530, estas características a las brujas:

También las cosas que hazen las bruxas o xorguinas son tan marauillosas que no se puede dar razon dellas por causas naturales que algunas dellas se vntan con vnos vnguentos y dizen ciertas palabras y saltan por la chiminea del hogar o por una ventana y van por el ayre $y$ en breue tiempo van a tierras muy lexos y tornan presto diziendo las cosas que alla passan (18).

Los conceptos de Ciruelo sobre los brujos europeos y la descripción de sus equivalentes andinos, of recida por Polo de Ondegardo, muestran analogías importantes: Según ambos autores,

(15) Philip Ainsworth Means, "Biblioteca Andina, Part One, the Chroniclers, or, the writers of the sixteenth and seventeenth centuries who treated of the prehispanic history and culture of the Andean countries", en Transactions of the Connecticut Academy of Arts and Sciences New Haven, 1928, no 29, págs. 271 525. Cita en pág. 429.

(16) Aspectos de la vida de Polo de Ondegardo han sido tratados por MEANS [15] (citas en págs. 428-430), Raúl Porras Barrenechea (Los cronistas del Perú. 1528-1650. Sanmartí, Lima, 1962. Citas en págs. 265-268) y Carlos Romero ("El licenciado Juan Polo de Ondegardo", en UrTeAGa y Romero [11], págs. XV-XXXVI. Citas en págs. XV-XXXVI).

(17) Al parecer se publicó por primera vez en 1530, a lo cual siguieron nueve ediciones sólo hasta el año 1557 (Agustín González de AmezúA, "Prólogo", en Martín de CASTAÑEGa, Tratado de las supersticiones $v$ hechicerias, (1. ${ }^{\mathrm{a}}$ ed. Logroño, 1529). Sociedad de Bibliófilos Españoles, segundá época XVII (Madrid, 1946), págs. V-XIX. Citas en págs. XV-XVI, XVI nota 9).

(18) Pedro Ciruelo, Reprouacion de las supersticiones $y$ hechicerias. Libro muy viline y necessario a todos los buenos christianos. (1.a ed. 1530). Alcalá, Pedro de Castro, 1548. Cita en Parte Prim. cap. II, f. viii (v). Subrayado de mí. 
los protagonistas de la brujería eran mujeres, quienes utilizaban un ungüento para volar. De esta manera podían recorrer grandes distancias en corto tiempo y fue así que se enteraban de lo que acontecía en regiones muy lejanas. Ambos autores coincidían además en la opinión de que los poderes extraordinarios de los brujos no hallaban explicación en fenómenos naturales.

A pesar de todas estas coincidencias, y no obstante el hecho de que Polo redactó su tratado probablemente en 1559 (19), y que por lo tanto posiblemente conocía el libro de Ciruelo, no parece verosímil que el licenciado Ondegardo haya copiado simplemente al teólogo español. Es de suponer más bien que Polo haya recurrido a un modelo bien conocido para describir el mundo de los adivinos indígenas, tan extraño e incomprensible para él y sus lectores. Así, de manera casi imperceptible, la creencia europea en las brujas se sobrepuso a la imagen de los adivinos del antiguo Perú y la borró.

Al tratar de reconstruir esta imagen, o sea la fenomenología por la cual se caracterizaban estos adivinos, en primer lugar es necesario que tachemos de la descripción de Ondegardo aquéllos elementos que con gran probabilidad se originaron más en la imaginación del autor que en observaciones concretas, como la afirmación que la brujería era ejercida con más frecuencia por mujeres viejas y que éstas usaban un ungüento (20). A nuestro entender, Polo mencionó éstos elementos sólo para apoyar su pretensión que los adivinos eran "como brujos", con lo cual quería decir que eran "como brujos españoles», y éstos -como se sabía- se reclutaban mayormente entre mujeres viejas (21). Fray Castañega, por ejemplo, dedicó un capítulo entero de su

(19) PORRAS [16], cita en pág. 267.

(20) Polo de Ondegardo [11], cita en cap. X, pág. 29. Con esto no queremos poner en duda de forma general el uso de alucinógenos por especialistas religiosos andinos. Por ejemplo está atestiguado el uso de la datura, la cual incluso actúa a través de la piel (véase Iris GAREIS, Religiöse Spezialisten des zentralen Andengebietes zur Zeit der Inka und während der spanischen Kolonialherrschaft. Münchner Beiträge zur Amerikanistik 19. Hohenschäftlarn, Klaus Renner Verlag 1987. Citas en págs. 309-314). Una cita muy interesante al respecto la proporciona Calancha, refiriéndose a la costa norte del Perú (Antonio de la Calancha, Coronica/ Moralizada/ del orden de / San Agvstin en el/ Perv, con svcesos egenplares/ vistos en esta monarqvia. Barcelona, Pedro Lacavalleria 1639. Citas en Lib. III cap. XVIII, págs 632-633). Sin embargo en el caso de los "adivinos-brujos", no nos parece bien fundada la afirmación de Polo de que usaron un ungüento.

(21) Cf. Le Roy Ladurie. [2], pág. 16, refiriéndose a la "caza de brujas" europea, "... les femmes jeunes et surtout mûres ou vieilles comptent pour 77,7 \% permi les accusé(e)s de sorcellerie". Véanse además Wolfgang BEHRINGER, "Erhob sich das ganze Land zu ihrer Ausrottung...' Hexenprozesse und Hexenverfolgungen in Europa", en Dül.mEN [2], págs. 150-153 y CARO [2], pág. 110. 
"Tratado de las supersticiones y hechicerías" (22), publicado en 1529, a la explicación, por qué, según su opinión, existían más brujas que brujos. Además, como vimos en la cita anterior del texto de Ciruelo, éste aludía también explícitamente a brujas, es decir a oficiantes femeninos. Sin embargo parece que Ondegardo no estaba demasiado seguro de sus afirmaciones, porque inició el párrafo de su texto sobre el "ungüento de las brujas" (23) con una locución bastante vaga: "algunos dizen" (24), como queriendo indicar que se aludía ya que no tenía prueba ninguna. Igualmente es poco convincente la advertencia de Polo que la brujería andina fue ejercida mayormente por mujeres viejas, porque en todo el párrafo respectivo empleó siempre la forma masculina del substantivo, y sólo una sola vez menciona a mujeres (25), limitando poco después su propia afirmación (26). Todo esto nos lleva a pensar que no se puede comprobar que los oficiantes eran en su mayoría mujeres, ni tampoco que usaban un ungüento para emprender el "vuelo de las brujas".

Cabe preguntarse entonces por qué tenía tanta importancia la cuestión de si estos "hechiceros" eran como "brujos". ¿No habrá sido, tal vez, porque se presumía una distinción importante entre ambas categorias de oficiantes? En efecto, revisando los tratados españoles de esa época, se halla una diferencia entre "hechiceros» y "brujos», ejemplificada en la obra de Fray Castañega, predicador de la Inquisición (27). Según el tratado de Castañega (1529) (28), los brujos eran individuos que habían pactado explícitamente con el diablo, abjurando de su fe católica, mientras que los hechiceros, aunque también sostenían un pacto con el demonio, no habían apostatado de su fe expressis verbis. Si los brujos, según éste modelo teórico, se caracterizaban por haber abandonado intencionadamente y por su propia voluntad la fe cristiana,

(22) Castañega [17], cita en cap. V, págs. 37-40.

(23) Acerca del "ungüento de las brujas" véanse por ejemplo: BächtolDSTÄubli [2] págs. 1.849-1.851; DüLmEN [2], págs. 111, 124; Hans Peter DuerR, Traumzeit, Uber die Grenze zwischen Wildnis und Zivilisation.. Syndikat, Frankfurt 1978. págs. 13-16; Thomas Hauschild, "Hexen und Drogen", en G. Volger y K. VON WELCK (eds.) Rausch und Realität. Hamburg 1982). Vol. 2, págs. 618-629; Jakob SPRENGER y Henricus INSTITORIS, Der Hexenhammer, $\left(1^{a}\right.$ ed. en latín 1487) (Munich, 5. ${ }^{\mathrm{a}}$ ed. 1986) Es la reproducción facsimilar de la $1 .^{\mathrm{a}}$ ed. en alemán: Berlín, 1906. Cita en la II. Parte, Kap. 3, pág. 49.

(24) Polo de Ondegardo [11], cita en cap. X, pág. 29.

(25) Idem, Ibidem.

(26) Idem pág. 30

(27) González de Amezua [17], pág. VIII.

(28) Castañega [17], citas en cap. IV, págs. 33-35. 
los hechiceros podían haber sucumbido inconscientemente a los artificios del diablo (29).

Por supuesto esta distinción entre brujos y hechiceros no se podía aplicar rigurosamente a la población indígena del Perú a mediados del siglo XVI, porque en esa época los indigenas eran considerados cristianos recientes, a quienes se tenía por poco firmes en la fe y a los que, por lo tanto, no se podía inculpar de apostasía (30). Quizás Polo intentaba aludir a esta situación al escribir que aquellos hechiceros andinos eran "como brujos". Tomando en consideración la doctrina teológica, vigente en aquel tiempo en España: estos adivinos no eran brujos en el sentido propio de la palabra, porque no habían apostatado de la fe católica, pero sí ostentaban las características exteriores de los brujos, como fueron presentados por la literatura correspondiente europea. Además es de suponer que Ondegardo no resaltó casualmente que los poderes extraordinarios de los "adivinos-brujos" andinos no tenían ninguna explicación "natural» (31), sino que con esto quería indicar el origen diabólico de esos poderes (32).

Sin embargo, otros elementos de la descripción de Polo -aunque demuestran igualmente analogías con las características de los «brujos» europeos- parecen ser autóctonos. El vuelo extático, por ejemplo, forma parte integrante del shamanismo en muchas regiones del mundo (33). En esto se encuadra muy bien la adición de Ondegardo, que los adivinos, antes de hacer sus pronósticos, se embriagaban ingiriendo gran cantidad de bebidas fermentadas y utilizando cierto alucinógeno (34). Tomando en consideración los datos conocidos acerca del uso de drogas y alucinógenos en los Andes en la época colonial temprana (35), no es exagerado

(29) Respecto a la importancia que tuvo el pacto con el diablo en sus diferentes formas durante la caza de brujas en Europa, véanse DüLmEN [2], págs. 98-108 y BEHRINGER [2], págs. 19-20.

(30) La población autóctona de Hispanoamérica no estaba sujeta a la Inquisición, trata el tema sobre Perú Duviols, La lutte [10], págs. 217-218.

(31) Polo De OndeGardo [11], cap. X, pág. 29.

(32) Véanse CASTAÑeGa [17], cap. VI, págs. 43-44 y especialmente Duviols, La lutte [10] págs. 42-43, además DüLMEN [2] págs. 98-99, 105, 107 y sobre todo 112. Los autores españoles contemporáneos emitian opiniones bastante heterogéneas acerca de los interrogantes, si los llaados "hechiceros" indígenas, es decir los especialistas religiosos autóúctonos, sostenian un pacto con el diablo y de que índole era aquel Duviols, Idem, págs. 22-23, 41-43.

(33) Mircea El.IADE, Schamanismus und archaische Ekstasetechnik. Suhrkamp Taschenbusch Wissenschaft $n^{\circ}$ 126, Frankf urt 1975, págs. 441-444.

(34) Polo DE Ondegardo [11], cap. X, pág. 29: “... se emborrachan hasta perder el juyzio..." Sobre el alucinógeno (villea) y las diferentes maneras de aplicarlo véase GAREIS [20] (págs. 301-305.

(35) GaRkis [20], págs. 299-314. 
pensar que bajo estas condiciones los adivinos descritos por Polo experimentaban también vuelos extáticos, cuanto más que existía entonces la creencia - vigente hasta la actualidad entre la población indigena-, que varios especialistas religiosos andinos poseen la facultad de volar (36).

Cabe mencionar que el poder de los "adivinos-brujos» de pronosticar el futuro no se fundaba principalmente en su facultad de volar, como parece sugerir el texto de Polo citado más arriba, sino se originaba sobre todo en la comunicación con los seres sobrenaturales. Esto lo demuestra otra cita del mismo autor: "hablan con el demonio, el qual les responde en ciertas piedras..." (37). Es decir, que estos adivinos consultaban el oráculo de una deidad andina. Esta misma forma de comunicación con las deidades andinas se halla documentada en varias fuentes históricas de la época sobre las zonas centro y surandina (38), donde Polo de Ondegardo vivió mucho tiempo (39) y a la que se refirió probablemente en primer lugar, aunque mencionó también las provincias de Huarochirí, Huánuco y Chachapoyas (40). Es de suponer que la costumbre de que los especialistas religiosos andinos hablasen con los dioses de esta manera se remonta ya a

(36) Pedro Sarmiento de Gamboa, "Segunda parte de la Historia general llamada Indica, la cual por mandado del excelentísimo señor Don Francísco de Toledo, virrey, gobernador y capitán general de los reinos del Pirú y mayordomo de la casa real de Castilla, compuso el capitán..." (1572), en R. PieTschmann (ed.) Geschichte des Inkareiches. Berlin, 1906, Göttingen, 1970, págs. III-CXVIII, 1-161. (Cita en cap. 46, pág. 90) nos informa acerca de un adivino muy famoso del cortejo del Inca Tapac Yupanqui que podía volar. Véase además CALANCHA [20] Lib. III cap. XVIII, pág. 628, cap. XIX, págs. 635, para datos sobre la costa norte del Perú y Hernández Principe para la sierra norteña (en: Pablo Joseph de Arriaga, Extirpación de la idolatría del Perú. (1621). Biblioteca de Autores Españoles, $n^{9}$ 209. Madrid, 1968, cap. X, pág. 232), que se refiere al caso del sacerdote de una huaca, quien volaba convertido en lechuza.

(37) Polo de Ondegardo [11], cap. X, pág. 29.

(38) Acosta [8], Lib. V cap. XXVI, pág. 372; Cовo [8], Lib. XIII cap. XXXVI, págs. 229-230; Pierre Duviols, "Un procès d'idolâtrie: Arequipa, 1671", en Fénix, n 16, Lima, 1966, págs. 198-211. 204, citando un documento de 1671; Historia General de la Compañia de Jesús en la Provincia del Perú, Crónica anónima de 1600 que trata del establecimiento y misiones de la Compañia de Jesús en los países de habla española en la América meridional. Francisco Mateos (ed.), Biblioteca "Missionalia Hispánica". CSIC., (Madrid, 1944). Citas en tomo II, cap. XIII, págs. 111-112 fs. 81-82; Murúa [8], tomo 2, Lib. II, cap. 32, págs. 117-118 fs. 264v-265; Antonio de VEGA, Historia del colegio y universidad de San Ignacio de Loyola de la ciudad del Cuzco. Biblioteca histórica peruana VI, Instituto de Investigaciones Históricas, Lima 1948. Citas en Lib. III, cap. II, págs. 102-103. VeGa (1948) y la Historia General de la Compañia.. (1944) reproducen en parte las mismas fuentes y son textos dependientes. Una descripción de esta forma particular de comunicación con las deidades se halla también en Gareis [20], pág. 328.

(39) Mians [15], cita en pág. 429.

(40) Polode Ondegiardo [11], cita en cap. X, págs. 29-30.

\section{R. l., 1993, n 198}


los tiempos prehispánicos y que por lo tanto es autóctona (41). Según las informaciones recogidas por Polo (42), este oficio fue ejercido en gran parte de los Andes Centrales y parece que los oficiantes podían ser tanto hombres como mujeres.

Repasando el texto de Polo se hace notorio el hecho que en la descripción de los "adivinos-brujos" falta un elemento constitutivo tanto del estereotipo europeo de la bruja como de nuestra definición del brujo (43), dado que Polo nunca menciona que estos adivinos hubieran tratado de dañar a una persona por medio de sus dotes extraordinarias. Por consiguiente no eran "brujos» en el sentido estricto del término: no lo eran según la imagen contemporánea que se tenía de las brujas (44), ni tampoco según nuestra definición. Sin embargo, en otra parte del mismo texto, Ondegardo (45) se refirió particularmente a "maleficadores», asegurando que la "magia» antisocial la ejercían en los Andes más frecuentemente mujeres viejas, muy experimentadas en el uso de diversas hierbas. No es necesario resaltar cuán poco convincente nos parece también en este caso la atribución de Polo a mujeres viejas como causantes de maleficios, ya que otros autores mencionan en este contexto a individuos masculinos (46). Aunque no coincidimos en todos los casos con las afirmaciones de Polo

(41) La continuidad de esta práctica religiosa durante varios siglos está atestiguada además por datos muy similares proporcionados en la literatura etnográfica moderna (Juvenal CASAVERDE ROJAS, "El mundo sobrenatural en una Comunidad", en $A P$, tomo Il, Cuzco, 1970, págs. 121-243. Antoinette FioravanTI MoLINIE, "Cure magique dans la vallée sacrée du Cuzco", en Journal de la Société des Américanistes, vol. 66, Paris, 1979), págs. 85-98. Manuel M. MARZAL, El mundo religioso de Urcos. Un estudio de antropologia religiosa y de pastoral campesina de los Andes. Instituto de Pastoral Andina Cuzco, 1971. Bernard Mishkin, "The comtemporary Quechua", en Julian H. STEWARD, ed., Handbook of South American Indians. Washington Smithsonian Institution, Bureau of American Ethnology, Bulletin 143. 1946, tomo 2 (1946), págs. 411-470. Cita en pág. 469; Harry TsCHOPIK, The Aymara of Chucuito, Perí. 1. Magic. Anthropological Papers of the American Museum of Natural History, vol. $44 n^{0} 2$ (Nueva York, 1951). Cita en págs. 264265.

(42) Polo de Ondegardo [11], cap. X, pág. 29-30.

(43) Véase la introducción al presente artículo.

(44) Acerca de la gran importancia del "daño" o "maleficium" en el estereotipo europeo de la bruja consúltense Bächtol.D-STÄUBLI [2], págs. 1.828, 1.841 y DölmEN [2], en págs. 99-101, 105.

(45) Polo De Ondegardo [11], cita en cap. X, pág. 28.

(46) Felipe Guaman Poma de Ayal.a, Nueva Crónica y Buen Gobierno, John V. Murra y Rolena Adorno, eds. Colección América Nuestra, América Antigua no 31. Siglo Vèintiuno XXI (México, 1980). Cita en págs. 247-248 f. 275; Cristóbal Mol.ina (e' Cuzqueño), "Fábulas y ritos de los incas" (ca. 1573), en Francisco A. LoAYza ed., Las crónicas de los Molinas. Pequeños Grandes Libros de Historia Americana, Serie 1, IV. Lima, 1943. Cita en pág. 23; véanse también los datos reunidos en GAREIS [20], págs. 268-269, 344-345. 
de Ondegardo - como es evidente en este párrafo-, sus escritos pertenecen a las fuentes históricas más tempranas que proporcionan datos sobre los brujos del antiguo Perú, por lo cual nos son imprescindibles. A ésto hay que añadir que muchos de los escritores posteriores a la década del 1560, en la cual Polo redactó su obra (47), le copiaron (48).

Además del uso de hierbas, con las que se suponía que los "maleficadores» preparaban múltiples venenos, también fue denunciada por autores de la época colonial temprana la creencia que usaban otros elementos para causar daño, como por ejemplo cabellos y uñas cortados (49), o también animales, sobre todo sapos. El autor indígena Guaman Poma de Ayala (50) describió cómo se realizaban maleficios utilizando sapos: Los brujos atravesaban con espinas los miembros del sapo, creyendo que al igual que el sapo sufre, sufría la persona a la que querían dañar. También se elaboraron figuras de sebo, que luego se traspasaban con alfileres o se quemaban. Se suponía que este maleficio provocaría en el individuo contra quien iba dirigido una enfermedad grave que después de un extenso sufrimiento, lo conduciría a la muerte (51).

Tales procedimientos se interpretaron, y siguen interpretándose hasta hoy en la literatura científica, como "magia imitativa» o "magia simpatética» (52). Esta interpretación, propagada princi-

(47) Porras [16], pág. 267.

(48) Véanse a esto las notas 9, 10, y 11 del presente artículo.

(49) Duviols [38], pág. 204, citando un proceso de idolatría del año 1671; Guaman Poma [46], cita en págs. 247-248 fs. 274-275; Joseph Laureano de MENA GoDOY, Información de méritos, servicios, 1653, AGI. Audiencia de Lima 246, cita. (Agradecemos la indicación de este documento a Hugo Pereyra Plasencia); MurúA [8], cita en Lib. II, cap. 25, págs. 99-100 f. 252v; Polo de ONDEGardo [11], cap. X, pág. 28. Refiriéndose en particular a creencias incaicas: Juan RUIZ DE ARCE, "Advertencias que hizo el fundador del vínculo y mayorazgo a los sucesores en él" (después de 1540), en Miguel Muñoz de SAN PEDro, Conite de Canilleros, (ed.), Tres testigos de la Conquista del Perú. Buenos Aires. Colección Austral 1.168. Buenos Aires, 1953. Buenos Aires, pág. 96.

(50) Idem [6] cita en pág. 248 f. 275.

(51) Luis J. BASTo GIRó, Salud y enfermedad en el campesino peruano del siglo XVII. Universidad Nacional Mayor de San Marcos Lima, 1957, págs. 17-18, proporciona datos de procesos contra idólatras; asimismo Pierre Duviols, "Camaquen, Upani: un concept animiste des anciens péruviens", en R. HaRTManN y U. OBEREM, eds. Amerikanistische Studien, Estudios Americanistas I-II, Festschrift für (Homenaje a) H. Trimborn. Anthropos Institut, St. Agustin, 1978/79, vol. I, págs. 132-144, Guaman Poma [46], pág. 248 f. 275; Letras annuas de la Pronincia del Perú, Lima 28-V-1635, RAH 9/3702 Doc. no 20, cita en f. 248; Polo [11], cita en cap. X, pág. 28.

(52) Así por ejemplo Walter Andritzky, ("Die Volksheiler in Peru während der spanisch-kolonialen Inquisition", en Anthropos vol. 82, St. Augustin, 1987, págs. 543-566), por nombrar sólo una publicación reciente. 
palmente por Frazer (53), implica que el maleficador comete una falta de lógica: al ejecutar la "magia homeopática», lo que equivaldría al maleficio anteriormente descrito con el sapo o la figura de sebo, según Frazer el oficiante comete el error de pensar "that things which resemble each other are the same" (54); mientras que el intento de causar daño, usando de uñas o cabellos cortados de la víctima, proceso que Frazer denomina «magia contagiosa" (55) se origina en su opinion, en la idea errónea "that things which have been in contact with each other are always in contact" (56).

Aplicando la terminología de Frazer a la descripción de fenómenos religiosos andinos, los estudiosos modernos necesariamente aceptan también las premisas que forman la base de las hipótesis de Frazer. Quiere esto decir que calificar los procedimientos de especialistas religiosos indígenas como "magia simpatética», significa acusarlos de incurrir en errores de lógica. Analizando más a fondo algunas fuentes históricas pronto descubrimos que por lo menos en algunos casos el modo de proceder de los maleficadores se originó en creencias completamente distintas, que de ninguna manera ostentan las faltas de lógica presupuestas por Frazer.

Demuestran ésto, con particular claridad, los apuntes que hizo un extirpador de idolatrías en el siglo XVII, la región norteña de los Andes Centrales. Este relata que cuando una bruja quería dañar una persona, modelaba primero una figura de sebo, sobre la que dejaba caer hojas de coca y chicha y quemándolo todo, pronunciaba al mismo tiempo el nombre de la víctima. La bruja creía vislumbrar entre las llamas una sombra, que era el «almacamaquen/upani» de la víctima. Rápidamente la bruja atravesaba el "alma» con espinas, la envolvía junto con la ceniza en lanas de diferentes colores y lo colocaba todo en un recipiente, que luego enterraba en el campo (57).

Es decir, que existía la creencia que la maleficadora se apoderaba y atacaba el "alma" de la víctima, y no solamente una imagen representativa. Así que, por lo menos en este caso, no se trataba de "magia simpatética». Esta interpretación se halla comprobada por el método curativo particular aplicado a las víctimas

(53) J. G. Frazer, The Golden Bough. A Studv in Magic and Religion. Part I: The Magic Art and the Evolution of Kings. Macmillan (London, 1911) pág. 52.

(54) Idern, pág. 53.

(55) Idem, pág. 52.

(56) Idern, págs. 53-54.

(57) Citado por Duviols [51], págs. 134-135. 
de tal brujería, porque se creía que la tarea más importante del curandero consistía en la búsqueda del "alma" robada. Cuando la había localizado, el curandero fabricaba una figura de sebo, como anteriormente lo había hecho la "bruja», llamó el "alma" del enfermo y prometió socorrerla. A esto apareció el "alma" en forma de "sombra" y se quejó ante el curandero de las dolencias que le causaban las espinas introducidas por la bruja. Para liberar el "alma», el curandero en primer lugar empolvó la "sombra" con harina de maíz blanco y luego dejó caer hojas de coca sobre ella. Purificada de esta manera, el "alma» finalmente pudo ser introducida otra vez en el cuerpo del enfermo. Después de esto, el curandero declaró sano a su paciente, dado que el "alma" había vuelto al cuerpo de éste (58).

Del texto referido queda muy claro que aquí la enfermedad fue atribuída al rapto del "alma» o sea del «alma-camaquen/upanì del paciente y no tenía que ver con "magia simpatética» ni con "magia imitativa».

Datos muy similares proporciona Phelippe de Medina (1650), visitador de idolatrias en el norte del Perú. Según sus notas, el daño se efectuó igualmente con el rapto del "alma" de la víctima. Al no ser posible recobrar su "alma», la persona afectada falleció (59). Posiblemente de la misma manera pueda ser interpretada una referencia de Arriaga en 1621 (60), reproducida por Villagomes en 1649 (61). Estos autores relatan que, para dañar a un indígena, los brujos fabricaban con sebo una figura de llama, mientras que para dañar a un español, usaban sebo de ganado europeo, alegando que el "alma" del europeo "que querían quemar, no comiera sebo de llama». Parece que estos maleficadores pensaban que el "alma» de la persona contra quien iba dirigido el maleficio, se posaba en la figura y que al quemar esta figura, quemarían al mismo tiempo el "alma» de su víctima. Si nuestra interpretación es correcta, en este caso las acciones de los brujos apuntaban también a dañar el "alma» misma de la víctima y no

(58) Citado por Duviols [51], pág. 135.

(59) Phelippe de MEDINA, Relación del Licenciado ... visitador general de las idolatrías del arçobispado de Lima imbiada al Il.mo y R.mo arçobispo della en que le da quenta de las que se han descubierto en el pueblo de Huacho donde a començado a bisitar desde 19 de febrero hasta 23 de março de 1650. AGI, Audiencia de Lima 303, fols. 6-6v.

(60) ARriaga [36], cap. IV, págs. 210-211.

(61) Pedro de Villagomes, Exortaciones e Instrucción acerca de las idolatrias de los Indios del Arzobispado de Lima (1649), CLDHP, Serie I, 12 (Lima 1919), cap. XLV, pág. 165. 
trataron de enfermar a una persona sólo por medio de quemar una imagen imitativa (62).

Aunque las fuentes citadas no son suficientes como para afirmar que todos los maleficios efectuados de la misma manera tenían como objetivo dañar a una víctima raptando su "alma", en todo caso demuestran que términos tales como "magia imitativa" etc., no deben ser aplicados sin previo examen riguroso de la documentación. Más aún, a nuestro parecer ya ha llegado el tiempo de tacharlos del discurso de la antropología moderna, porque estos términos, como también el hablar de «leyes de la magia" (63) hacen creer que se trata de resultados comprobados científicamente (64). Sin embargo, estas supuestas «leyes de la magia" no son sino hipótesis e interpretaciones adelantadas por Frazer. Al no tener en cuenta el carácter hipotético de las "leyes» formuladas por Frazer, el investigador fácilmente incurre en el error de contentarse clasificando los respectivos fenómenos como una u otra categoría de magia, dejando de lado totalmente el método científico. De esta manera las categorías propuestas por Frazer facilitan un pretexto para evitar la argumentación científica, desde luego más trabajosa.

En las páginas anteriores hicimos referencia a brujos y curanderos, como si estas hubieran sido categorias fácilmente diferenciables. Con esto quisimos indicar solamente la función del especialista religioso a la que nos referíamos, sin postular que en el antiguo Perú haya existido una separación rigurosa entre «magos buenos" y "malos", o sea, entre especialistas de "magia blanca" y "negra». Por el contrario, esta distinción, si es posible, sólo lo sería en algunos pocos casos, ya que un individuo podía ejercer varios oficios religiosos $\mathrm{y}$, por consiguiente, podía ser al mismo tiempo sacerdote, curandero y brujo (65). A esto hay que añadir la semejanza entre el método curativo y la forma como se efectuaba el daño, la cual demuestra que la mayoría de los especialistas religiosos podía actuar tantọ para el bien como para el mal de su prójimo.

(62) Acerca de esta problemática véanse las interesantes consideraciones teóricas de Wolfgang BRüCKNER, "Oberlegungen zur Magietheorie. Vom Zauber mit Bildern" en L. Petzold, ed. Magie und Religion. Wege der Forschung CCCXXXVII, Wissenschaftliche Buchgesellschaft Darmstadt, 1978, págs. 404-419.

(63) Frazer [53], págs. 52, 54.

(64) Asi por ejemplo ANDRITZKy [52], pág. 546.

(65) Véase por ejemplo Сово [8], cita en Lib. XIII cap. XXXIII, pág. 225; y GarEIS [20], págs. 20, 247-248, 419, 501 . 
El rapto del alma también formó la base de maleficios ejecutados por otra categoría de brujos denominados cauchu en quechua (66). Según el jesuita José de Arriaga (67) quien proporcionó informaciones muy detalladas sobre ellos (68), fueron característicos sobre todo de las culturas de la costa peruana. Runapmicuc (69) era otra denominación usada para los mismos brujos. Esta palabra denomina la manera de proceder de estos brujos, ya que según Arriaga (70) significa «el que come hombres». Según los datos recogidos por este mismo autor (71), se creía que los runapmicuc mataban personas, para lo cual entraban por las noches donde dormían sus víctimas y les chupaban la sangre sin ser notados. Después cocinaban la sangre, que se convertía por este procedimiento en carne, que era consumida en reuniones con otros runapmicuc.

Resulta bastante difícil formarse un juicio sobre la autenticidad del relato de Arriaga. Aunque éste asegura que sus informaciones provinieron de la confesión de un cauchu arrepentido, algunos elementos parecen no ser autóctonos. Como la reunión nocturna de los runapmicuc, en la que se adoró también al diablo, quien presidió la junta de los brujos en forma de "león» o de «tigre» (72). Como una mera coincidencia puede ser considerado el hecho que en aquel tiempo en Europa se acusaba a los

(66) Diego González Holguin, Vocabulario de la Lengua General de todo el Perú. Llamada Lengua Quichua o del Inca. Instituto de Historia, Univ. Nac. Mayor de San Marcos. Lima, 1952. págs. 52, 438; Vocabulario y phrasis en la lengua general de los indios del Perú, llamada Quichua y en la lengua española. El más copioso y elegante que hasta ahora se ha impreso. G. EscoBAR RIsco (ed.), Universidad Nacional Mayor de San Marcos, Lima 1951. pág. 23. Resulta interesante, que GonzÁLEz Holguin (1608) supone que el maleficio del cauchu se originó en el mal de ojo, mientras que el "Vocabulario" (1586) refiere otro método de maleficar, dando como traducción del verbo "cauchuni", además de "embrujar", la noción "torcer hilo". Por Guaman Poma [46], pág. 248, f. 275) sabemos que en los Andes se utilizaba hilo torcido a la izquierda para dañar. J. J. von TschUDI, (Die KechuaSprache. Dritte Abteilung. Wöterbuch. Kaiserlich-Konigl. Hof-und Staatsdruckerei 1853, pág. 125 propone en su vocabulario una tercera interpretación porque dice acerca del cauchuk o cauchu, que era un "un hechicero que con ceremonias misteriosas arrancó hojas de árboles para utilizarlas en hechicerías". Es posible que la traducción de tschudi, que data del siglo XIX, sea una interpretación tardía y secundaria del término cauchu.

(67) ARRiaga [36], cap. III, pág. 208.

(68) Villagomes [62], copió a Arriaga en cap. XLIII, págs. 155-156.

(69) Basto GiRón, cita en procesos de idolatrías del siglo XVII la variación [51], pág. 70, "Runi, micui" Guamán Poma [46] apunta "Runi micoc"; pág. 285 f. 310. El vocabulario de Tschuil [66] pág. 463 reza: "Runa micuk, el antropófago".

(70) ARRIAGia [36], cap. III, pág. 208.

(71) Idem, cap. III, pág. 208.

(72) Idem, ibidem. 
brujos de matar personas, chupándoles la sangre (73), mientras que la presunta adoración del diablo seguramente tenía su origen en tradiciones europeas (74).

Quizás Arriaga y otros autores españoles, a causa de ciertas analogías existentes entre los métodos para hacer daño en Europa y América, pensaron que sus conocimientos acerca de los brujos europeos, eran también válidos para los cauchu o runapmicuc. La comparación del texto de Arriaga con la relación que hizo el agustino Antonio de la Calancha de la reunión de los cauchu demuestra muy bien en qué medida las descripciones contemporáneas de los brujos -o sea de los oficiantes que se tenían por tales- fueron impregnados de conceptos europeos sobre la brujería. El libro de Arriaga se publicó en 1621, mientras que la obra de Calancha salió de la imprenta casi dos décadas más tarde, en 1638.

La visión que ofrece el padre Calancha (75) de la reunión nocturna de los cauchu, utilizando notas del padre jesuita Luis de Teruel (76), ostenta a primera vista más analogías con un sabbat de "brujas" europeo, como lo imaginaron los "cazadores de brujas" en los siglos XVI y XVII (77), que con la información que transmite Arriaga sobre la junta de maleficadores andinos. En la obra de Calancha pasan al primer plano de la descripción, y adquieren particular importancia dos elementos constitutivos de la imagen europea de la bruja: la adoración del diablo y el relato de las orgías desenfrenadas a las que se entregan los participantes del "sabbat" (78). Aunque menciona también que algunos brujos en esta reunión se dedican a ejercer la magia negra, ésta se efectúo con la ayuda del diablo, quien recompensaba así la fidelidad de sus prosélitos (79). Recordemos que Arria-

(73) Carlo Ginzburg, Hexensabbat, Entzifferung einer nächtlichen Geschichte. Trad de Storia notturna... (1989) Verlag Klaus Wagenbach Berlin, 1980, págs. 128, 130, 157; Henry Charles LeA, A History of the Inquisition of Middle Ages. Nueva York, 1956, tomo III, págs. 500, 502-503.

(74) Véase también la interpretación que da Duvıoıs [6], págs. LXX-LXXI) sobre los mismos datos.

(75) Cal.ancha, [20], Lib. III, cap. XVIII, pág. 632.

(76) Idem, pág. 631.

(77) Compárense CARo Baroja [2], págs. 115-124, 207-214, 221-227, el artículo muy interesante de DüLMEN [2], en especial págs. 96-97, 119-120, 127-130 y la importante obra de GinZBURG [73] (especialmente págs. 18, 20, 31, 260-261, 289301; Idem, Die Benandanti. Feldkulte und Hexenwesen im 16. und 17, Jahrhundert. Frankfurt M., 1980. págs. 148, 170) LEA [73] tomo III, págs. 500ss.

(78) Cal.ANCha [20], Lib. IIl cap. XVIII, pág. 632.

(79) Idem, ibidem. 
ga (80) centró su relato de la reunión de los cauchu en las acciones de los brujos para causar daño, refiriéndose sólo de paso a la adoración del diablo. Incluso la misma figura del diablo sufrió una transformación, como señaló Duviols (81). Ya no se presenta en la reunión de los cauchu bajo la forma de león o tigre, como en la versión de Arriaga (82), lo que bien podía ser la manifestación de una deidad autóctona (83) sino que en la relación de Calancha (84), además de aparecer como león o perro (85), adopta la figura de «cabrón», apariencia habitual del diablo en el "sabbat" europeo (86).

Otra discrepancia entre los dos textos se manifiesta respecto a los individuos a quienes se acusaba de asistir a la junta. El cuadro vívido que pinta Calancha (87) de la reunión de los cauchu, atestigua la participación de mujeres, especialmente en los actos orgiásticos, mientras que Arriaga (88) no menciona ni la asistencia de mujeres ni tampoco excesos de carácter sexual. El se refiere a una reunión de individuos masculinos exclusivamente, con el objetivo principal de ejercer maleficios.

Aunque es de suponer que Arriaga ya había incorporado en su descripción elementos europeos, como la presunta adoración del diablo, la adaptación al estereotipo europeo de la bruja se hace mucho más ostensible en el cuadro que nos of rece Calancha. Como ya advertimos al discutir la relación de Polo de Ondegardo sobre los "brujos-adivinos», también en este caso creemos que los datos ofrecidos por Arriaga y Calancha acerca de los cauchu o runapmicuc no eran una mera invención de estos autores. Más bien es de pensar que ambos — probablemente sin darse cuenta de ello- ajustaron las informaciones que habian recogido sobre los cauchu a sus propios conceptos europeos e interpretaron los

(80) Idem, ARriaga [36], cap. III, pág. 208.

(81) Duviols [6], pág. LXXI.

(82) ARriaga [36], cap. III, pág. 208.

(83) Así por ejemplo la Carta anua de la provincia del Pirí del año 1613 (RAH, ms. 9/3660: $\mathrm{n}^{2}$ 89) proporciona el dato interesante que el dios andino se presentaba a veces a los indigenas con patas de lion".

(84) Calancha [20], Lib. III, cap. XVIII, pág. 632.

(85) También en las fuentes europeas se menciona al perro como posible manifestación del diablo, CARO [2], pág. 123.

(86) Idem, págs. 120, 207, 221; DülMEN [2], págs. 123-124.

(87) Calancha [20], Lib. III, cap. XVIII, pág. 632.

(88) ARriagi [36], cap. III, pág. 208. 
datos poniéndolos de relieve sobre este trasfondo europeo (89). A este respecto, una alusión de Calancha es particularmente revelante. Al iniciar su relato sobre la reunión de los cauchu escribe:

Los brujos de la Barranca tenían sus juntas como las del Aquelarre de tierra de Burgos, en el pueblo de Cegarramurde... (90)

Es decir, para describir a los que él considera los brujos de la costa peruana, empieza por citar el aquelarre o sea el sabbat de Zugarramurdi, lugar de presuntas juntas de brujas situado en el norte de España, que adquirió triste celebridad por los procesos inquisitoriales y el auto de fe de Logroño de 1610 (91), y que aún sigue mencionándose incluso en las tradiciones orales actuales de la región (92). Así, Calancha al mismo tiempo que define su punto de vista, propone un modelo conocido mediante el cual tendrán que ser interpretadas las informaciones sobre los cauchu. Con esto encamina sus lectores hacia una interpretación de los datos, determinada de antemano (93). De esta forma, el estereo-

(89) Calancha [20] en Lib. III, cap. XVII, pág. 631 declara remitirse a los apuntes del jesuita Luis de Teruel. Por lo tanto no podemos decidir cuál de los dos escritores ajustó los informaciones acerca de los cauchu al ideario europeo, o si ambos lo hicieron. De todos modos, es de notar que en otro capítulo de su obra, sobre apariciones del diablo. Calancha (Lib. IIf, cap. XIX) demostró su considerable erudición respecto al estereotipo europeo de la bruja. Además de autores de la edad antigua y teólogos de la época medieval citaba además muchos tratados contemporáneos de teóricos de la caza de brujas: Así por ejemplo, se refirió a Binsfeld cuyo tratado sobre brujas salió a luz en 1591 (CARO [2], pág. 158), como también el libro de Rémy publicado en 1595. (CARO [2], pág. 155) y a la obra de Martín del Río, impreso por vez primera en 1599. Sobre todo esta última obra tuvo gran importancia en la evolución del estereotipo del sabbat (Behringer [2], págs. 29-30; Düllmen [2], pág. 96). Para una crítica de los textos de Arriaga y Calancha, véase también Duviols [6], págs. LXX-LXXI.

(90) Calancha [20], Lib. III, cap. XVIII, pág. 632.

(91) José M. de Barandiaran, Brujerias y brujas en los relatos populares vascos. Txertoa (San Sebastián, 1984, págs. 17, 58; CARO BAROJA [2], págs. 202, 207, 219-228. En esta ocasión siete personas fueron entregadas a la hoguera. En comparación con los condenados en procesos españoles anteriores a éste y a procesos franceses contemproáneos, el número de personas condenadas a perecer en la hoguera no era elevado (CARo [2], pág. 228). Sin embargo, los sucesos de Logroño en 1610 tuvieron particular importancia para la historia de la caza de brujas en España (CARO [2], págs. 219-239), que toma otro rumbo al del resto de Europa (véase BEHRINGer [2], págs. 27, 43-44; IDEM [21], citas en págs. 139-140, 157).

(92) BaRANDIARAN [91], págs. 17, 25, 80, 87.

(93) MuRúa se refiere expressis verbis a brujas españolas al tratar de los maleficadores andinos [8], Lib. II, cap. 25, págs. 99-100 f. 252v. 
tipo europeo de la bruja se impuso una vez más al concepto andino y lo falséó.

Repasando las informaciones de Arriaga y Calancha, podemos colegir de sus textos que algunos elementos de sus descripciones - como la adoración del diablo y las orgías desenfrenadaspueden identificarse fácilmente como pertenecientes a la tradición europea. Otros elementos, por el contrario, encuadran muy bien en el ideario andino. Este es el caso particular de una referencia de Arriaga (94), quien relata que los cauchu habían afirmado en sus reuniones, que querían comer el "alma" de tal o cual persona. Aparentemente existía la creencia, entre los habitantes de la región, que los cauchu, al ingerir la sangre de sus víctimas, consumían a la vez el alma de las mismas. Ya observamos que en las culturas andinas la pérdida del alma era (y es) considerada la causa de graves enfermedades, las cuales incluso podían provocar la muerte de la persona afectada (95). Por lo tanto, parece que el maleficio de los cauchu de la costa se producía como consecuencia del rapto del alma de los víctimas, al igual que en el caso de los brujos de la sierra. Sin embargo, hay que resaltar una diferencia importante entre los brujos de la costa y los de la sierra. En las fuentes consultadas no encontramos evidencias de que en la sierra hayan existido congregaciones de maleficadores. Parece que los brujos de la sierra actuaban con más frecuencia individualmente, cada uno de por su lado. A la inversa, los cauchu de los Llanos, no solamente se reunían en las juntas nocturnas, sino también formaban organizaciones fijas en los pueblos de la comarca. Arriaga (96) y Villagomes (97) afirman que en cada uno de los diferentes ayllu o parcialidades hubo un "maestro" («brujo»). En el siglo XVII éstos fueron también denominados "capitanes". A cada uno de estos maestros o capitanes se hallaban subordinados algunos "discípulos" y "soldados». Las fuentes históricas no ofrecen datos sobre las posibles diferencias existentes entre la función de discípulo y de soldado. Tampoco se desprende de los textos el motivo por el cual se utilizaron justamente los términos españoles de capitán y de soldado para denominar los varios grados de la jerarquía de estos «brujos». ¿Habían elegido los mismos cauchu estas denominaciones o fueron los españoles

(94) Arriaga [36], cap. III, pág. 208.

(95) Datos bibliográficos para la época reciente en Garkis [20], pág. 340 y 340 nota 4.

(96) Arriagia [36], cap. III, pág. 208.

(97) VILl.AGOMES [61], cap. XLIII, pág. 155. 
quienes los designaron asi, pareciéndoles que la organización de los cauchu era de tipo militar? Ya no es posible averiguarlo, pero el hecho de que se hallan usado términos pertenecientes al campo semántico militar, parece indicar que la organización de los cauchu se caracterizó por una disciplina rígida, y que existía una organización jerárquica.

A principios del siglo XVII los españoles lograron identificar 63 «brujos-cauchu» en solo cuatro poblaciones de la costa norteña (98). Este elevado número justifica el interrogante sobre la probabilidad de que tantas personas se hubieran dedicado exclusivamente a la brujería (99). Arriaga no mencionó otras funciones de los "capitanes", pero Calancha(100) en su "Crónica Moralizada" (101) afirma que los "capitanes" de los Llanos también habían sido "maestros dogmatizadores». Este término, sin embargo, fue usado generalmente por los españoles para denominar a sacerdotes de deidades indígenas, pero no se empleó para referirse a brujos. Calancha advierte además que los mismos funcionarios religiosos en la sierra se llamaron «licenciados» (102). Esta denominación tampoco se aplicó a los brujos en general, sino a sacer-

(98) Arriaga [36], cap. III, pág. 209; Testimonio de Luis de Teruel en Fernando de AvenDANo, Informacion de servicios (1618-1620). AGI, Audiencia de Lima 327, f. 29v; "Relación de los medios que se an puesto para la extirpación de la ydolatria de los yndios, deste arçobispado de los Reyes y de los pueblos que se an visitado en el tiempo que a que gouierna el ex.mo. s.or Principe de Esquilache y de los buenos efectos que se an seguido" (1619). AGI, Audiencía de Lima 38, ${ }^{2}$ 2 lib. IV, fs. 392r-397r. Citas en fs. 393r-396v.

(99) La cifra de "brujos maléficos" es bastante elevada comparándola con el número de ot ros especialistas religiosos en los mismos pueblos: además de los 63 brujos, solo fueron descubiertos 78 sacerdotes autóctonos en la visita de aquellos lugares (Relación de los medios. [98], f. 393r). Incluso hubo un pueblo (Barranca) donde el número de brujos superaba el de los sacerdotes indígenas (Fernando de AVENDAÑo, "Testimonio de la visita de la extirpación de la ydolatria en que absoluio el doctor ... doce mill y ciento y treinta, personas en ocho, años que uisito como consta de la ultima hoja deste testimonio, 1623 años", AGI. Audiencia de Lima 329; fol. 14; Sin embargo, tomando en cuenta el número total de 1.618 especialistas religiosos indigenas que fueron descubiertos durante toda la visita, son pocos los 63 brujos y en la mayoría de los pueblos los visitadores no lograron identificar ningún brujo maléfico.

(100) Calancha [20], Lib. III, cap. XVIII, pág. 627.

(101) La obra de Calancha complementa muy bien el libro de Arriaga, ya que respecto a la costa norteña, Calancha usó informaciones recogidas por Luis de Teruel en una visita de idolatrías, que éte había llevado a cabo a principios del siglo XVII en compañía de Arriaga, Pierre Duviols, "El Contra idolatriam de Luis de Teruel y una verión primeriza del mito de Pachacamac-Vichama" en Revista Andina vol. 1, no 2 Cuzco, 1983, págs. 385-392. Así que los escritos de Arriaga y Calancha ofrecen dos visiones o dos puntos de vista distintos acerca de los especialistas religiosos de la misma región.

(102) Calancha [20], Lib. III cap. XVIII, pág. 627. 
dotes indigenas (103), los cuales en lo Andes solian ejercer una multitud de tareas diferentes (104).

También los vínculos estrechos que unían los capitanes y sus ayudantes con ciertos ayllu y parcialidades de los pueblos, parece indicar que además de dedicarse a la brujería realizaban otras tareas. Incluso es posible que los antiguos habitantes de la costa peruana no equipararan las actividades de los cauchu exclusivamente con la brujería o con la magia antisocial, sino que quizás también se les atribuían funciones organizatorias, motivo por el cual se los denominó "capitanes" y "soldados». Sin embargo hay que añadir, que en aquella época la creencia de que los brujos se hallaban organizados de forma militar y que estas organizaciones eran encabezadas por capitanes estaba también bastante difundida en Europa (105). Por lo tanto, el hecho de que los autores españoles de la época emplearan las denominaciones capitanes y soldados podría denunciar asimismo la influencia de conceptos europeos. Finalmente el autor andino Santacruz Pachacuti (106) enumeró los "cauchos" junto con los, laycas (107), humos (108), uallaviças, contiviças y otros especialistas religiosos, considerados como brujos.

Los datos que actualmente pueden ser reunidos sobre los cauchu o runapmicuc, nos llevan a concluir que no es posible

(103) "Carta anua de la provincia del Pirú del año 1613" RAH Ms. 9/3660 no 89; en Duviols [38] pág. 207, citando documentación de un proceso contra idólatras (Arequipa 1671); Historia General de la Compañia (1600) op. cit. [38], tomo II, cap. XIfI, pág. 127 f. 96; Juan PÉrEZ BocANEGRA, Ritval Formvlario, e Institvcion de curas, para Administrar a los Natvrales de este Revno, los santos Sacramentos del Baptismo, Confirmación, Eucaristia, y Viatico, Penitencia, Extremavncion, y Matrimonio, con advertencias muy necessarias. Por el Bachiller ... presbitero, en la lengua Quechua general: examinador en ella, y en la Aymara, en este Obispado... Geronymo de Contreras Lima, 1631, pág. 129. Véasé también ARRIAGA [36], (cap. XIX, págs. 264-265) aunque sus notas al respecto son algo difusas, Murúa, [8] Lib. II, cap. 26, págs. 101-102 f. 254 atribuye el término licenciado a curanderos.

(104) CoBo [8], Lib. XIII cap. XXXIII: 225; Gareis [20], págs. 7-20.

(105) BäChtOlD-STÄUBli [2], pág. 1.845.

(106) Joan de Santacruz Pachacuti Yamoui Salcamaygua, "Relación de antigüedades deste reyno del Pirú" (ca. 1613-1620), en Marcos JimÉnEZ DE LA ESPADA ed., Tres relaciones de antigüedades peruanas. Madrid, 1879, Ministerio de Fomento, págs. 231-328. Citas en págs. 266, 315.

(107) El vocablo layca parece haber sufrido una reinterpretación interesante. Mientras que las fuentes históricas de la temprana época colonial sugieren que con "layca" se denominaron sacerdotes indigenas con la variedad de tareas caracteristica, en la actualidad este término adopta el sentido de "brujo maléfico" (véase la discusión en GAREIS [20], págs. 254-255; además ID., Llama und Alpaca in der Religion der rezenten Bewohner des zentralen und südlichen Andengebietes. Hohenschäftlarn, 1982, Münchner Beiträge zur Amerikanistik 6. págs. 101, 106; TschopIK [41], págs. 219, 224-225).

(108) GaREıs [20], págs. 252-254. 
determinar con certeza si estos eran exclusivamente brujos o si ejercían también otras tareas. Aunque creemos que esta última hipótesis es la acertada, las fuentes históricas sólo atestiguan los actos de brujería y por el momento no disponemos de otras informaciones que pudieran modificar este cuadro (109).

\section{LOS BRUJOS Y LA SOCIEDAD PREHISPÁNICA}

Creemos que la documentación histórica ofrecida aquí nos permite contestar afirmativamente al primer interrogatorio expuesto en el preámbulo, sobre la existencia de brujos en el antiguo Perú. De entre las varias categorías de especialistas religiosos andinos analizadas, parece que algunos no sólo fueron calificados como maleficadores por los españoles, sino también por la misma población indígena. A nuestro parecer, éste fue el caso tanto con los cauchu como con los brujos serranos. Es de notar que su oficio, según la visión indígena, con gran probabilidad no se hallaba restringido al de "brujo maleficador», sino que generalmente tenía varias tareas a su cargo (110).

La característica más sobresaliente del oficiante en función de brujo, según nuestra definición, era su capacidad de causar daño por medio de artes mágicas. Por lo tanto, surge el interrogante: ¿cómo procedieron los miembros de la sociedad prehispánica ante la amenaza que representaba la actuación de los brujos, para la comunidad? Y dado que durante las ultimas décadas que precedieron a la Conquista española, las culturas andinas estaban sujetas al estado centralizado de los inca, es posible preguntarse qué papel desempeñaban los brujos en la vida política del imperio incaico.

Varias citas en las fuentes escritas de los siglos XVI y XVII documentan que entre los habitantes del antiguo Perú el temor a la brujería se hallaba bastante difundido. Este miedo se refleja-

(109) Acerca de las funciones de los cauchu en la sociedad andina véanse también las consideraciones de Duviols [6] (págs. LIII-LV), quien en esta ocasión hace referencia a CARO [2], págs. 116-117, y especialmente 121-123) y GinzBURG [77]. Estos autores trabajaron sobre organizaciones dualistas en sociedades europeas de los siglos XVI y XVII y sus interpretaciones podrian ser muy útiles para entender mejor el papel de los cauchu en los Andes. No obstante, la comparación de los datos europeos con los andinos se ve dificultada por el hecho de que sólo disponemos de un número muy reducido de fuentes históricas que proporcionan datos acerca de los cauchu.

(110) Compárese también M. Silvi:rblatt en "Dioses y diablos" [5], págs. 3844) "The Evolution", [65] págs. 417-425. 
ba en la manera cuidadosa con que se recogian y guardaban uñas y cabellos cortados o dientes caídos (111).

Además, parece que las personas afectadas por la brujería trataron de evitar que los conflictos afloraran a la superficie, temiendo los poderes extraordinarios de los maleficadores. Así, por ejemplo, contó un hombre al padre Arriaga, que cierta noche había entrado un caucho en su casa, aparentemente con el propósito de dañarle, pero que ante sus súplicas, desistió de sus malos intentos. El hombre que había sido atacado por el caucho, no osó denunciar al brujo por un lapso de muchos años, temiendo su venganza (112). Asimismo en el caso de la bruja serrana, que raptó el alma de su víctima para enterrarla después en el campo, no disponemos de informaciones que sugieran que las personas afectadas hayan intentado vengarse. El curandero se contentó con restituir el «alma» al cuerpo del enfermo, pero no existen datos acerca de un posible castigo de la bruja (113). Aunque las escasas citas no permiten juicios definitivos, parece indicar que a nivel del pueblo o del grupo local en general no hubo castigos públicos de individuos considerados como brujos maleficadores. Por el contrario, la legislación incaica sí imponía penas dracónicas a los brujos maléficos. Si alguien era declarado culpable de ser brujo no solo se mataba a éste, sino a toda su familia, a excepción de los niños de pecho. La casa del brujo era arrasada y el lugar donde había estado edificada se cubría con cal (114). Un dibujo

(111) Datos de un proceso de idolatría del año 1671, Duviols [38], pág. 204. Además Guaman Poma [46], págs. 247-248 fs. 274-275; Mena Godoy [49] (f. 55ss.) Murúa [8], Lib. II, cap. 25, págs. 99-100 f. 252v; Polo de OndeGardo [11], cap. X, pág. 28, y RUIZ DE ARCE, [49], pág. 96 que se refiere especialmente a la cultura incaica. Véase también John Howland Rowe, "Inca culture at the time of the Spanish Conquest", en Handboock of South American Indians. Washington, 1946, tomo 2, pág. 314.

(112) ARriaga [36], cap. III, pág. 209.

(113) Texto citado por Duviols [51], pág. 135.

(114) "Carta anua de la Provincia del Perú 1587", en Monumenta Peruana. Ed. Antonio Egaña. Roma, 1966, vol. IV, doc. 60, págs. 259-260; СoBo [8], Lib. XII cap. XXVI, pág. 116; "En la gran ciudad del Cuzco ... se haga averiguación de lo usos y costumbres que los indios nautrales desta tierra tenían en el modo de su gobierno y de sus pleitos en tiempo de su gentilidad, y sobre lo demás en la dicha real cédula contenido..." 28 marzo 1582, en José Toribio Medina (ed.), La imprenta en Lima (1584-1824). Santiago, 1904 vol. 1, págs. 187-199. Guaman Poma [46], págs. 163, f. 187, 247 f. 274, 285, I. 311; Polo de ONdEGardo [11], cap. X, pág. 29. Inca Garcilaso de la Vega Comentarios reales de los Incas. Biblioteca Ayacucho Caracas, 1976, Lib. III, cap. IV, págs. 130-131 afirma que ciertos brujos habian sido quemados vivos en el estado inca, pero la obra de este autor está imprégnada de conceptos europeos, los cuales son aqui particularmente notorios. 
de Guanau Poma, en su "Coronica» (115) muestra cómo los funcionarios incaicos mataron los brujos y sus familiares, golpeándoles con grandes porras de madera (Fig. 1). Aunque no sabemos concretamente, de qué modo se comprobaba la culpabilidad de los brujos, es de suponer que los funcionarios incaicos frecuentemente seguian denuncias, y que los delatores podían ser incluso vecinos del mismo individuo denunciado como brujo (116).

Parece que en el estado inca a veces fueron inculpados individuos como brujos debido a razones políticas. Un documento de la mitad del siglo, XVI (1559), que se refiere a la conquista de la costa central llevada a cabo por el Inca Tupac Yupanqui, nos trasmite un suceso interesante al respecto: El soberano inca venció en esa ocasión al señor de Collique, el cual murió en la lucha. Un tributario de éste, el curaca del lugar de Quivi, que había acudido a socorrer al señor de Collique, fue finalmente sometido por los incas, aunque no se le privó de inmediato de su dignidad y siguió gobernando la región de Quivi. Después de cierto tiempo, el curaca de Quivi fue inculpado de haber intentado embrujar al soberano inca con la ayuda de una deidad lugareña, la huaca Acupayllata. El juez incaico, encomendado con la instrucción de la causa, declaró culpable finalmente al curaca de Quivi, del crimen de brujería contra el Inca y, por consiguiente, de haber conspirado contra el soberano. A consecuencia de esta sentencia, el curaca y parte de la élite local fueron conducidos al Cuzco y ejecutados allí como traidores. Según el documento, los

(115) Felipe Guaman Poma de Ayala, Nueva Crónica y Buen Gobierno. (Codex péruvien illustré). Travaux et Mémoires de l'Institut d'Ethnologie 23, Paris, 1936. Cita en f. 310.

(116) Véanse las referencias en Cristóbal de Castro y Diego de OrTega Morejón ("Relación y declaración del modo que este valle de Chincha y sus comarcanos se gobernaban antes que hobiesen ingas y después que los hobo hasta que los cristianos entraron en esta tierra" (1558), en Colección de documentos inéditos para la Historia de España L Madrid, 1867, tomo 50, págs. 206-220. Cita en pág. 211), en la "Relación del origen é gobierno que los Ingas tuvieron y del que había antes que ellos señoreasen a los indios deste reino, y de que tiempo, y de otras cosas que al gobierno convenía, declarados por señores que sirivieron al Inga Yupanqui y a Topainga Yupanqui, y a Guaina Capac, y a Guáscar Inga" (después de 1575), (en Medina [114], tomo 1, pág 205) y en Fernando de SaNTILLAN, "Relación del origen, descendencia, política y gobierno de los Incas" (ca. 1563), en JIMÉNEz DE LA EsPADA [106] pág. 19). Hay que advertir, que estos tres textos son casi idénticos y por lo tanto no pueden ser considerados como fuentes históricas independientes. Acerca de las dependencias entre estos documentos véanse Juan Carlos CRESPO, "La relación de Chincha, 1558", en Historia y Cultura Lima, 1978, no 8, pág. 188 y Guillermo LoHmanN Villena, "Únas notas acerca de curiosos paralelismos y correspondencias entre cuatro documentos históricos sobre la época incaica", en Fénix 16, Lima 1966, nº 16, pág. 176. 





incas mataron también a todos los hombres de Quivi, perdonando la vida sólo a las mujeres y a los niños, bajo la condición de que se olvidaran para siempre de la huaca Acupayllata (117). En el caso del curaca y de los nobles de Quivi, llama sobre todo la atención la asociación entre brujería y rebelión, que establecieron los incas.

Otros relatos contemporáneos también indican que la atención de los incas se dirigía especialmente a los brujos, considerándoles una amenaza para la salud del Inca o perjudicial para el estado incaico. Cabello Balboa, menciona una cárcel, erigida por mandado del Inca Tupac Yupanqui, para aprisionar diversos oficiantes religiosos:

en estas echauan a los maléficos con hechizos y ponzoñas, y a los encantadores, falsos prophetas, y malos sacerdotes (118).

Sobre todo la combinación de maléficos y falsos prophetas hace pensar que la introducción de esta nueva cárcel por el Inca se debía a motivos políticos en el sentido más amplio del término.

Una referencia muy similar a la de Cabello Balboa se halla en la obra de Guaman Poma (Fig. 2) (119). Además nos informa Murúa que existían ciertos individuos:

Que usaban de hechizerías permitidas por sus leyes, pero siempre mesclaban con ellas cosas prohibidas y ansí, si el ynga lo sabía, los castigaua con tanto rigor que a ellos y a sus descendientes quitaba la vida (120).

Aunque Murúa no especifica en qué consistían «las cosas prohibidas», su texto nos lleva a pensar que se trataba de regla-

(117) Documento publicado por María Rostworowski DE Diez CANSEco, "Etnohistoria de un valle costeño durante el Tahunatinsuyu", en Revista del Museo Nacional, Lima, 1967-68. $\mathrm{n}^{\mathrm{Q}}$ 36, pág. 11. Véase especialmente el testimonio de Cristóbal Caxallaupe 1559 (IB. pág. 57 f. 196), además M. RosTwOROWSKI DE DíEZ CANSECo, "Las etnias del valle del Chillón", en ID., Etnia y sociedad: costa peruana prehispánica. Lima, Instituto de Estudios Peruanos, 1977, pág. 33. Más tarde se establecieron mitima en Quivi por orden del inca (ROSTWOROWSKI, "Etnohistoria", pág. 19).

(118) Miguel Cabello Balboa, Miscelánea Antártica. Una historia del Perú antiguo. Instituto de Etnología, Univ. Nac. Mayor de San Marcos (Lima, 1951), cita en la III Parte, cap. 20, pág. 354. Cabello, Balboa terminó su crónica en el año 1586. MEans [15], pág. 319.

(119) Guaman Poma [115], fol. 310.

(120) Murúa [8], Lib. II, cap. 32, pág. 117, fol. 264v. 





mentos introducidos por los incas para controlar también a los especialistas religiosos, ya que no pertenecían al clero estatal.

En todo caso podemos deducir de los documentos citados que en la legislación del imperio inca el delito de «brujería contra el Inca", equivalía en cierto modo al de traición política. Esta asociación entre brujería y «rebelión política» establecida por los Incas, también explica el rigor de los castigos aplicados a los brujos maléficos. Fuera de ello, es posible pensar que algunas acusaciones por "brujería" se formularon en realidad debido a motivos políticos. Al fin y al cabo no era nada fácil de revisar tales acusaciones y aún mucho más difícil refutarlas, por lo cual eran armas muy apropiadas en la lucha por el poder político. Por medio de estas acusaciones era bastante fácil eliminar a adversarios políticos (121).

Desde este punto de vista, seguramente tanto el curaca de Quivi, que fue ajusticiado por haber cometido el crimen de brujería, al igual que otras personas, consideradas como brujos por los incas, habían interpretado sus acciones de manera completamente distinta. Sin embargo, muy pocas veces se conservó la opinión de los pueblos subyugados por los incas, y la visión de la mayoría de los habitantes de los Andes. Generalmente sólo conocemos la interpretación de los incas, ya que ellos reinaban cuando llegaron los españoles, a quienes trasmitieron su visión de los acontecimientos. De modo que la imagen de los brujos del antiguo Perú, pintada por las fuentes históricas, probablemente no sólo fue distorsionada porque a los conquistadores españoles no les era posible desprenderse de sus conceptos europeos al describir las religiones andinas, sino que esa imagen había sido ya alterada por los incas. Las interpretaciones de éstos y su visión de la realidad andina sólo deben ser evaluadas, tomando en consideración los objetivos de la política imperialista del estado inca.

(121) Dos autores del siglo XVI hacen referencia a un caso de brujería que se produjo en un linaje incaico, en el cual a nuestro parecer resalta con particular claridad la motivación política de la acusación: A la muerte de Topa Inca una mujer del fallecido Inca fue acusada de haberlo matado con hechizos y ponzoña. La mujer fue prendida y la mataron. Su hijo que, según algunos, era el príncipe heredero del trono incaico, fue desterrado. El hecho que la acusación de brujería contra la mujer del Inca fuera levantada por otra mujer de Topa Inca y madre de otro pretendiente al trono, hace pensar que el principal motivo para levantar esta inculpación fue el deseo de deshacerse de un rival en la lucha por el poder. Cabello Balboa [118], Terc. Parte cap. 20, pág. 358 y Sarmiento de Gamboa [36], cap. 55, pág. 103. 


\section{CONClusiones}

Los datos históricos reunidos en el presente artículo demuestran que en el antiguo Perú existían individuos que practicaban la brujería para dañar a otros miembros de la sociedad. Sin embargo, señalamos diversos obstáculos que dificultan la reconstrucción histórica del concepto del «brujo maleficador" que se tenía en el antiguo Perú, ya que la imagen del brujo prehispánico proporcionada por las fuentes históricas, no solamente fue distorsionada por los autores coloniales, españoles e indígenas - asimilándola al estereotipo europeo de la bruja - sino es posible también que ya anteriormente habría sido falseada a causa de ciertos conceptos políticos vigentes en el imperio de los incas. Además, las informaciones sobre brujos maléficos en los Andes prehispánicos son escasas y fragmentarias.

Al revisar los datos sobre varios tipos de especialistas religiosos relacionados con la brujería en las fuentes históricas, la categoría de oficiantes analizada en primer lugar no mostró más que semejanzas exteriores con el concepto del brujo vigente entonces en Europa. Constatamos que la actividad principal de este grupo de oficiantes fue la adivinación y que no existen datos que sugieran que hayan ejercido la brujería para causar daño. Las analogías sorprendentes que ostentan la descripción de estos adivinos y el estereotipo de la bruja europea se originaron, a nuestro parecer, en una asimilación llevada a cabo por el autor del relato histórico. Este, probablemente a causa de algunas semejanzas exteriores y más bien superficiales entre los adivinos andinos y el estereotipo europeo del brujo $-\mathrm{y}$ tal vez sin ser consciente de ello- ajustó su descripción de los adivinos andinos al concepto del brujo europeo.

Esta transformación fue tan considerable que el lector moderno incluso podría llegar a la conclusión que se trata de una descripción de brujos europeo y no de datos sobre oficiantes andinos. Sin embargo, estudiando el texto más detenidamente, descubrimos varios elementos autóctonos que caracterizaban estos oficiantes como especialistas religiosos andinos.

Otra categoría de oficiantes analizada aquí y mencionada frecuentemente en las fuentes históricas, mataba con ponzoña o causaba daño utilizando sapos y figuritas de sebo, raptando las "almas" de sus víctimas. Los caucho o runapmicuc, otro grupo de "maleficadores», que actuaba sobre todo en la costa norte del Perú, parece haber dañado sus víctimas también mediante el 
rapto de sus almas, aunque su modo de proceder difería del empleado por el grupo anterior.

En las descripciones sobre los cauchu también se puso de manifiesto la tendencia de asimilar a éstos a la imagen que se tenía entonces de los brujos en Europa, aunque los caucho al igual que los brujos que usaban sapos y figurinas de sebo, según las fuentes históricas, fueron considerados también en las sociedades indígenas como «brujos maléficos». Dejando de lado supuestas características de estos brujos, mencionadas en las descripciones, que son de clara procedencia europea, -como la adoración del diablo y orgías sexuales- la discrepancia más importante entre la imagen ofrecida por los autores de aquella época y nuestra concepción de estos brujos, reside en que les atribuimos otras funciones. En las fuentes históricas el «brujomaleficador" es con gran frecuencia un personaje nefasto, cuyo principal objetivo es causar el mal. Aunque no se mencionan otras funciones, la documentación consultada parece indicar que tal separación rigurosa entre «brujos malos" y "oficiantes buenos" no existía en las culturas andinas prehispánicas, sino que generalmente las funciones de los diversos especialistas religiosos oscilaban entre ambos extremos y que un funcionario podía actuar, según la circunstancia, tanto para el bien como para el mal de su prójimo.

Finalmente hay que advertir que en los diferentes casos de distorsiones de las fuentes históricas aquí analizados, la manera cómo el concepto europeo se superponía al andino era siempre la misma: Nunca se trató de meras invenciones de los autores contemporáneos, sino que cierta semejanza - aunque fuera superficial- entre los brujos andinos y los europeos servía de base para la transformación paulatina de la imagen de los brujos andinos en aquello que conocían los autores españoles. Es decir, estas analogías fueron el eje o las vías por las cuales se introducían elementos constitutivos del estereotipo europeo de la bruja al concepto andino del brujo, transformándolo paulatinamente, hasta que éste presentaba tan solo débiles huellas de lo que había caracterizado al brujo en el antiguo Perú. 